\title{
A Special Method to Confirm Non-Feasibility of Secondary Spread of Downy Mildew Systemic Infection between Sorghum Seedlings of Similar Age
}

\author{
Heminder Singh, Rajkumar H. Garampalli* \\ Department of Studies in Botany, University of Mysore, Manasagangotri, MYSORE, Karnataka State, 570006, India \\ dosinbotany.raj@gmail.com
}

\begin{abstract}
A method has been devised to test the possibility of spread of secondary infection in green-house experiments in case of downy mildew of sorghum. Treatment pots were planted with inoculated sprouts in the peripheral ring and sown with seeds in the centre to study disease transmission from periphery to the centre. In the treatment pots containing a peripheral ring of 6 days old sporulating seedlings and central seedlings of 1-2 days age, $46 \%$ disease transmission from periphery to centre was recorded. In pots with 6 days old peripheral sporulating seedlings and central seedlings of 3-4 days age, disease transmission was $13 \%$ and in pots where peripheral and central seedlings were both of 6 days age, no transmission was recorded. Results indicate that disease transmission between siblings of same age is not feasible in greenhouse or field conditions.
\end{abstract}

Keywords Sorghum, Downy Mildew, Sibling Shower, Secondary Transmission

\section{Introduction}

Sorghum (Sorghum bicolor (L.) Moench) is an agronomically important cereal crop, which stands fourth only after Rice, Wheat and Maize in terms of production (1). It feeds vast population in low income group in South Asia and Africa. Besides, it is used as fodder crop all over the world. Sweet Sorghum is now finding application as energy crop for production of ethanol. Sorghum is primarily a dry-land, rain-fed, low input crop. Cultivation of rain-fed crops is on the rise all over world due to ever increasing gap in demand and supply of irrigation water, caused by population explosion and depletion of water resources. Downy mildew of sorghum, caused by Peronosclerospora sorghi (W. Weston \& Uppal) C.G. Shaw, is one of the serious diseases of the crop in tropics. It causes significant damage in South India, especially South Karnataka, according to All India Cordinated Sorghum Improvement Project, 2005-06 report(2). The pathogen reproduces sexually by oospores which become soil-borne to enable over-wintering of pathogen and asexually by conidia which get air-borne causing secondary spread of disease. Conidia are produced in field and greenhouse conditions between 1am to 4am and

* Corresponding author:

rajkumarhg@yahoo.co.in (Rajkumar H. Garampalli)

Published online at http://journal.sapub.org/plant

Copyright (C) 2012 Scientific \& Academic Publishing. All Rights Reserved being ephemeral, survive only a few hours without infecting new host tissue (3).Seedlings are more susceptible to conidial infection at young age and are known to gain resistance with advancing age (4). In greenhouse experiments, after artificial inoculation, the symptoms of chlorosis and conidial sporulation appear within 7 days of sprout or seedling inoculation $(5,6)$. In experiments, where there is need to record the data about disease incidence resulting from artificial inoculation, the diseased plants need to be removed from pots immediately after observation to avoid spread of secondary infection (7). In such cases, even if disease count is taken twice a day viz. morning and evening, after the removal of diseased plants late in the evening, next morning more sporulated seedlings are spotted and removed. Since sporulation takes place in the night, the inevitable air borne dispersal of conidia during night time raises doubt of spread of secondary infection, resulting in faulty data collection.

Thus, sibling shower test was devised to find out if transmission of systemic disease by conidia is possible between seedlings of same age. That is, since sporulation from a infected seedling generally takes place on sixth day of sprout inoculation, whether a six day old sporulating seedling can transmit the disease to a sibling of same age present in close proximity, in greenhouse conditions.

\section{Material and Methods}

\subsection{Preparation of Pathogen Inoculum}


The systemically infected uniformly sporulating leaves were collected from downy mildew sick-field from $5: 30 \mathrm{pm}$ to $6.00 \mathrm{pm}$. Leaves were immediately brought to lab, cleaned with moist cotton to remove previous sporulation, dust, etc., dried with tissue paper and cut into small pieces and placed in petri-plates lined with moist filter paper, with abaxial surface of leaves upwards.

In the morning at $4 \mathrm{am}$, the leaves were washed in chilled water $\left(5^{\circ} \mathrm{c}\right)$ to collect the conidia. The conidial suspension was shaken vigorously for 1-2 minutes to separate conidia from conidiophores. The suspension was filtered through single layer muslin cloth, the final volume was adjusted to requirement. Tween-20 was added at the rate of one drop per litre. A sample of $10 \mathrm{ml}$ was drawn from conidial suspension and subjected to haemocytometer count (5).

\subsection{Inoculation}

240 seeds of sorghum DMS-652 variety were placed in a plastic cup with filter paper lined bottom. Water was added to dip the seeds and decanted three hours later. The cup was covered with petri-plate lid and incubated at room temperature for 42 hours to obtain sprouts. Conidial suspension $\left(8.0 \times 10^{4} / \mathrm{ml}\right)$ was poured into the cup containing 42 hour old sprouts and allowed to stand. After 13 minutes, suspension was decanted carefully to the last drop, sprouts were spread uniformly at the bottom of cup. Cup was covered with petri-plate lid and incubated at room temperature for 12 hour to obtain infected seedlings to be used in green house experiment (5).

\subsection{Sibling Shower Test}

Green house experiment comprised of one control and three treatments. Experiment was conducted in triplicates. Pots of 6 inch diameter with capacity to hold $1.25 \mathrm{~kg}$ of soil were used. The control pots were sown with 35 seeds each, three days prior to sprout-inoculation-day, which germinated out of soil on the day of sprout inoculation. All the treated pots were sown at the rate of 17 seeds per pot on different days (as described ahead), in the central region of pots, leaving the peripheral ring vacant (unseeded). The pots of first treatment were labeled as $-3 \mathrm{D}$ and sown three days prior to sprout-inoculation-day. The pots of second treatment were labeled as $-1 \mathrm{D}$ and sown one day prior to sprout-inoculation-day. The pots of third treatment were labeled $+1 \mathrm{D}$ and sown one day after sprout-inoculation-day. All the treatment pots were planted with conidia inoculated sprouts in the peripheral ring at the rate of 10-12 sprouts per pot after 12 hours of post-inoculation-incubation. The seedlings obtained from the inoculated sprouts, planted in peripheral ring of treatment pots, showed leaf-base chlorosis symptom on the evening of 5th day of inoculation and sporulated on the morning of 6th day. On the first day of sporulation, the age of seedlings in the central region of pots in first, second, third treatment was 5-6 days, 3-4 days and 1-2 days respectively. The replicates of control and treatments were kept in individual cluster with distance of at least one foot between the clusters.

\subsection{Disease Incidence}

Disease incidence in the form of systemic infection was recorded for all the pots twice a day for 21 days after sporulation. Diseased plants were removed immediately after observation to avoid spread of secondary infection. Presence of any one of the two characteristics symptoms i.e., chlorosis of leaf base or sporulation on lower surface of leaf was followed as criteria for identification of infection (8). In case, an entire leaf showed faded green colour, presence of conidia on lower side served as confirmatory sign of infection. Plants showing doubtful symptoms were marked and on 20th day of disease reading, such pots were irrigated in evening and covered with polythene bags to create moist conditions, followed by early morning observation for symptoms. The pots were monitored for disease symptoms regularly and final reading was obtained on 21st day of sporulation. Small petri-plates of $2 \mathrm{~cm}$ diameter containing $1.25 \%$ water-agar were placed in each pot on second day of sporulation to record spores deposited per $\mathrm{cm}$ square over night. Experiment was conducted three times with similar results and mean of three readings was taken for calculations (Fig. 1, 2).

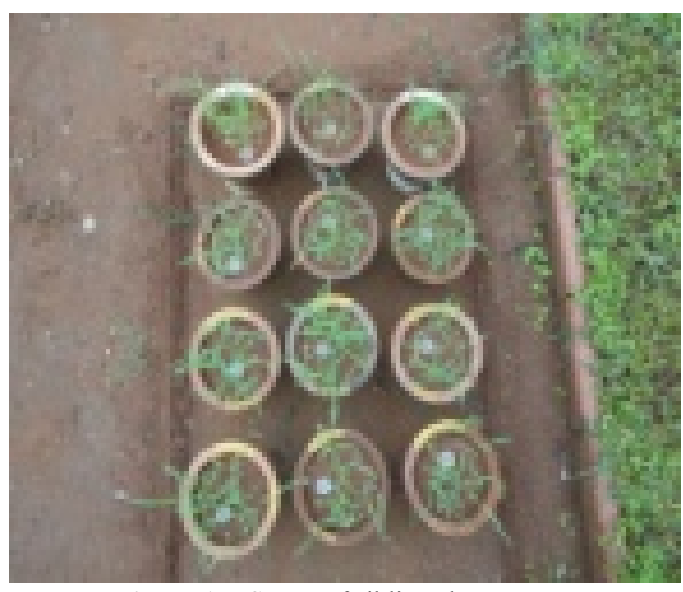

Figure 1. Set up of sibling shower test

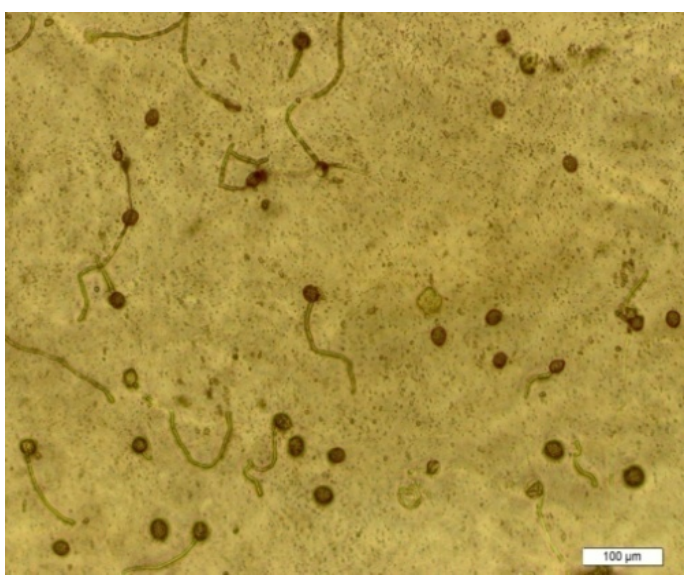

Figure 2. Count of conidia deposited in petri-plates 
Experiments were conducted at University of Mysore, Mysore, Karnataka, India, in August 2011. Mysore is located at $12.30^{\circ} \mathrm{N} 76.65^{\circ} \mathrm{E}$ and has average altitude of 770 meters. The city experiences mean annual daily minimum temperature of $19.1^{\circ} \mathrm{C}$ (which ranges from $16.1^{\circ} \mathrm{C}$ in January to $21.4^{\circ} \mathrm{C}$ in April). Mean annual daily maximum temperature is $29.7^{\circ} \mathrm{C}$ (which ranges from $27.5^{\circ} \mathrm{C}$ in December to $34.4^{\circ} \mathrm{C}$ in April) (9). Monthly average morning relative humidity ranges from 76\% in March to $93 \%$ in August and September. Monthly average evening relative humidity ranges from $29 \%$ in March to 69\% in August (10).

\subsection{Statistical Analysis}

Standard deviation was calculated using Microsoft excel software. Data was subjected to one way analysis of variance (ANOVA), followed by Tukey's post test at $\mathrm{P} \leq 0.05$ level of significance using Graphpad prism 5 software.

\section{Results}

The disease monitoring for a period of 21 days showed that $-3 \mathrm{D}$ pots in which peripheral and central seedlings were both of 6 days age at sporulation, showed no disease transmission from peripheral to central seedlings.

The -1D pots, in which the central seedlings were two days younger than peripheral seedlings, showed $13.3 \%$ disease transmission. The $+1 \mathrm{D}$ pots, in which the central seedlings were 4 days younger than peripheral seedling, showed $46.6 \%$ disease transmission (Table. 1 \& Figure.3).

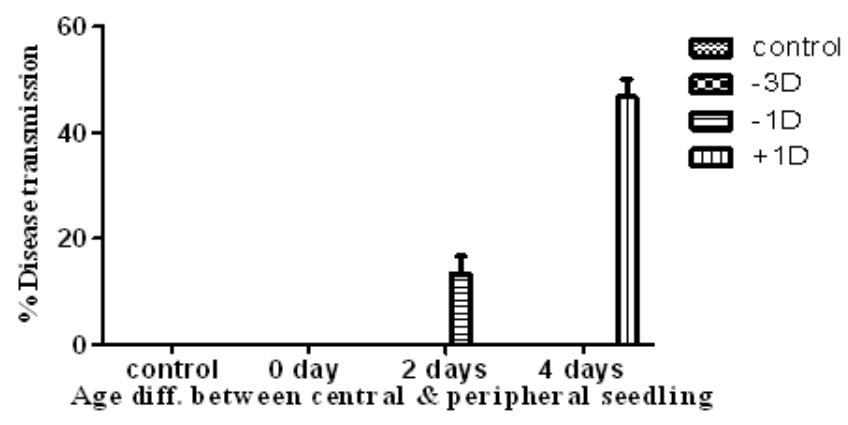

Figure 3. Relation between seeding age $\&$ disease transmission

\section{Discussion}

Table 1. Sibling shower test

\begin{tabular}{|c|c|c|c|c|c|c|}
\hline Treatments & $\begin{array}{c}\text { Mean periph- } \\
\text { eral seed- } \\
\text { lings/pot }\end{array}$ & $\begin{array}{c}\text { Mean sporulating } \\
\text { peripheral seed- } \\
\text { ling/pot }\end{array}$ & $\begin{array}{c}\text { Mean cen- } \\
\text { tral seed- } \\
\text { ling/pot }\end{array}$ & $\begin{array}{c}\text { Age diff. be- } \\
\text { tween peripheral } \\
\& \text { central seed- } \\
\text { lings }\end{array}$ & $\begin{array}{c}\text { \% disease transmis- } \\
\text { sion to central seed- } \\
\text { lings/pot }\end{array}$ & $\begin{array}{c}\text { No. of spores deposited } \\
\text { / sq.cm over-night in } \\
\text { petri plates }\end{array}$ \\
\hline Control & 10 & 0 & 10 & -- & 0 & $40 \pm 13.8$ \\
\hline -3D & 11 & 7 & 10 & 0 & 0 & $357 \pm 36$ \\
\hline -1D & 11 & 7 & 10 & 2 days & $13.3 \pm 5.7^{*}$ & $202 \pm 37$ \\
\hline +1D & 11 & 8 & 10 & 4 days & $46.6 \pm 5.7^{* * *}$ & $434 \pm 41$ \\
\hline
\end{tabular}

There are previous reports suggesting reduction in susceptibility of seedlings with advancing age, in case of Sorghum downy mildew (3). The sibling shower test confirms that, transmission of systemic disease between plants of same age group is not generally feasible, so disease cannot be easily transmitted within a greenhouse. Usually in such greenhouse experiments, a negative control, a positive control and an overall control are employed. Negative control pots record disease incidence resulting from inoculation by spore suspension, positive control pots record disease incidence resulting from fungicide treatment followed by inoculation and the overall control pots which are sprayed only with distilled water, record disease incidence resulting from inoculum present in seeds, soil or air, if any. Overall control pots can serve to test the spread of secondary infection in green house from pot to pot but sibling shower method tests the spread of secondary infection from plant to plant within a pot.

Secondary spread of disease within a field is also thus inferred to be improbable as all seeds are sown on the same day. The transmission of systemic disease is possible only from neighboring fields with older plants to emerging seedlings in adjoining field. That is, if there is no sorghum fields in the surroundings the threat of secondary systemic infection is almost eliminated, making the fungicide spray avoidable. The test also suggests a schedule for fungicide spray. Since the test shows that the six day old seedlings become resistant enough to with-stand air borne inoculum load, one spray of fungicide daily in late afternoon for initial five days after germination can give almost complete protection to crop from air borne infection. The results can help in fine-tuning the spray schedule to get optimum results with minimum usage of chemicals. The results obtained may be also applicable in case of downy mildew of Maize, which is a world-wide disease caused by the same pathogen. The test can be adapted for other air borne diseases where disease incidence resulting from artificial inoculation needs to be recorded but chances of secondary spread exits. The main problem in controlling diseases in graminaceous crops concerns economic feasibility due to high cost of chemicals and low commercial value of crop (Kenneth, 1981). Optimizing the use of chemicals would be of economic and ecological significance. 


\section{ACKNOWLEDGMENTS}

The authors are thankful to University Grants Commission for financial support to carry out this work. The authors acknowledge Dr. Y. D. Narayana, Principal Scientist (Pathology), All India Co-ordinated Sorghum Improvement Project, University of Agricultural Sciences, Dharwad, Karnataka State, India for providing DMS-652 seeds.

\section{REFERENCES}

[1] FAOSTAT, 2009.( www.fao.org)

[2] AICSIP Report 2005-06 (http://nic jowar.ap.nic.in/aicsip 2005/agm 06-co ordinating team report).

[3] Populer, C. (1981). Epidemiol-ogy of downy mildews. In:Spencer, D. M. (ed) The downy mildews. Academic Press, London. Pp 58.
[4] Kenneth, R. G. (1981). Downy mildews or graminaceous crops. . In:Spencer, D. M. (ed) The downy mildews. Aca-demic Press, London. Pp 384-91.

[5] Safeeulla KM, (1976). In: Biol-ogy and control of Downy Mildews of Pearl millet, Sorghum andFinger millet. Final Technical Report: Project A7-CR-352 PL-480, The Agricultural Research Service, USA and The Uni-versity of Mysore, India. pp 132.

[6] Narayana, Y. D., Mughogho, L.K., Bandyopadhyay, R. 1995. Evaluation of green house in-oculation technique to screen sorghum for resistance to downy mildew. Euphyti-ca, 86:49-53.

[7] Craig, J., Frederiksen R.A., Od-vody, G.N. and Szerszen, J. 1987. Effects of Herbicide Antidotes on Sorghum Downy Mildew. Phytopathology. 77:1530-1532.

[8] Frederiksen, R. A. 1980 . Sorg-hum downy mildew in the United States: Overview and outlook. Plant Disease. 64: 903-908.

[9] http://www.imd.gov.in/section/climate/mysore2.htm

[10] www.weather re-ports.com/India/Mysore 